\title{
Determination of Carbonyl Compounds in Exhaled Cigarette Smoke*
}

\author{
by \\ Serban Moldoveanu, William Coleman III, Jonathan Wilkins
}

R.J. Reynolds Tobacco Co., 950 Reynolds Boulevard, Winston-Salem, NC 27105, USA, e-mail: moldovs@rjrt.com

\section{SUMMARY}

This paper presents the findings on a quantitative evaluation of carbonyl levels in exhaled cigarette smoke from human subjects. The cigarettes evaluated include products with $5.0 \mathrm{mg}$ 'tar', $10.6 \mathrm{mg}$ 'tar' and $16.2 \mathrm{mg}$ 'tar', where 'tar' is defined as the weight of total wet particulate matter (TPM) minus the weight of nicotine and water, and the cigarettes are smoked following U.S. Federal Trade Commission (FTC) recommendations. The measured levels of carbonyls in the exhaled smoke were compared with calculated yields of carbonyls in the inhaled smoke and a retention efficiency was obtained. The number of human subjects included a total of ten smokers for the $10.6 \mathrm{mg}$ ' $t a r$ ', five for the $16.2 \mathrm{mg}$ 'tar', and five for the $5.0 \mathrm{mg}$ ' $\mathrm{tar}$ ' product, each subject smoking three cigarettes. The analyzed carbonyl compounds included several aldehydes (formaldehyde, acetaldehyde, acrolein, propionaldehyde, crotonaldehyde and $n$-butyraldehyde), and two ketones (acetone and 2-butanone). The smoke collection from the human subjects was vacuum assisted. Exhaled smoke was collected on Cambridge pads pretreated with a solution of dinitrophenylhydrazine (DNPH) followed by high performance liquid chromatography (HPLC) analysis of the dinitrophenylhydrazones of the carbonyl compounds. The cigarette butts from the smokers were collected and analyzed for nicotine. The nicotine levels for the cigarette butts from the smokers were used to calculate the level of carbonyls in the inhaled smoke, based on calibration curves. These were generated separately by analyzing the carbonyls in smoke and the nicotine in the cigarette butts obtained by machine smoking under different puffing regimes. The comparison of the level of carbonyl compounds in exhaled smoke with that from the inhaled smoke showed high retention of all the carbonyls. The retention of aldehydes was above $95 \%$ for all three different tar levels cigarettes. The ketones were retained with a slightly lower efficiency. Acetone was retained in the range of $90 \%$ to $95 \%$. The retention for 2-butanone showed a larger scatter compared to other results but it also appeared to be slightly less absorbed than the aldehydes, with an average retention around $95 \%$. The retention of acetaldehyde and acetone by human smokers was previously reported in literature and the findings from this study are in very good agreement with these result. [Beitr. Tabakforsch. Int. 22 (2007) 346-357]

\section{ZUSAMMENFASSUNG}

In dieser Arbeit werden die Ergebnisse einer Bestimmung der Carbonylkonzentrationen im exhalierten Zigarettenrauch präsentiert. Die untersuchten Zigaretten umfassen Produkte mit 5,0 mg, 10,6 mg und 16,2 mg Kondensat/Zigarette, wobei Kondensat als Gesamtpartikelmasse (TPM) abzüglich des Nikotins und des Wassers definiert wird und die Zigaretten nach den Normen der U.S. Federal Trade Commission (FTC) abgeraucht wurden. Die gemessenen Carbonylkonzentrationen im exhalierten Rauch wurden mit der berechneten Carbonylaufnahme aus dem inhalierten Rauch verglichen und die Retentionseffizienz wurde ermittelt. Zehn Raucher rauchten Produkte mit einem Kondensatgehalt von 10,6 mg, fünf Raucher rauchten Zigaretten mit 16,2 mg Kondensat und fünf Raucher rauchten Zigaretten mit 5,0 mg Kondensat, wobei jeder Raucher drei Zigaretten rauchte. Unter den untersuchten Carbonylverbindungen befanden sich mehrere Aldehyde (Formaldehyd, Acetaldehyd, Acrolein, Propionaldehyd, Crotonaldehyd, und n-Butyraldehyd) und zwei Ketone (Aceton und 2-Butanon). Die Sammlung der Rauchproben erfolgte Vakuum-unterstützt. Der exhalierte Rauch wurde auf Cambridgefiltern gesammelt, die mit einer Lösung aus Dinitrophenylhydrazin (DNPH) vorbehandelt waren. Nachfolgend wurden die Dinitrophenylhydrazone der Carbonyl- 
verbindungen mittels Hochdruck-Flüssigkeitschromatographie (HPLC) analysiert. Die Zigarettenstummel der Raucher wurden gesammelt und auf ihren Nikotingehalt untersucht. Anhand des Nikotingehalts der Zigarettenstummel wurden die Carbonylkonzentrationen des inhalierten Rauches auf der Basis von Eichkurven berechnet. Diese wurden unabhängig ermittelt, indem die Carbonylverbindungen im Rauch und das Nikotin in den Zigarettenstummeln durch maschinelles Abrauchen unter verschiedenen Abrauchbedingungen bestimmt wurden. Der Vergleich der Konzentration der Carbonylverbindungen im exhalierten Rauch mit derjenigen im inhalierten Rauch wies auf eine hohe Retention aller Carbonylverbindungen hin. Die Retention der Aldehyde lag bei den Zigaretten aller drei Kondensatlevel über 95\%. Die Ketone wurden zu einem etwas geringeren Prozentsatz reteniert. Bei Aceton lag die Retention zwischen $90 \%$ und $95 \%$. Die Retention von 2Butanon zeigte eine größere Streuung im Vergleich zu den anderen Ergebnissen, 2-Butanon schien aber ebenfalls mit einer durchschnittlichen Retention von ungefähr $95 \%$ etwas weniger absorbiert zu werden als die Aldehyde. Die Retention der Acetaldehyde und des Acetons beim Raucher sind in guter Übereinstimmung mit früher in der Literatur angegebenen Werten. [Beitr. Tabakforsch. Int. 22 (2007) 346-357]

\section{RESUME}

Dans cette étude les teneurs en composés carbonyles dans la fumée exhalée par les fumeurs sont évaluées quantitativement. Les cigarettes étudiées ont un rendement respectivement de 5,0;10,6 et 16,2 mg de goudron ; le goudron étant définit comme matière particulaire totale (TPM) exempte de nicotine et l'eau. Les cigarettes ont été fumées selon les conditions normalisées de la Federal Trade Commission (FTC). Les teneurs en composés carbonyles dans la fumée exhalée ont été comparées avec les rendements calculés en carbonyles dans la fumée inhalée, pour obtenir l'efficacité de rétention. Dans cette étude, dix fumeurs ont fumé les cigarettes à 10,6 mg de goudron, cinq ont fumé les cigarettes à $16,2 \mathrm{mg}$ de goudron et également cinq les cigarettes à 5,0 mg de goudron, tous les fumeurs fumant trois cigarettes. Les composés carbonyles analysés comportent plusieurs aldéhydes (formaldéhyde, acétaldéhyde, acroléine, propionaldéhyde, crotonaldéhyde et $n$ butyraldéhyde), et deux cétones (acétone et 2-butanone). La collecte de la fumée exhalée par les fumeurs a partiellement été réalisée sous vide. La fumée exhalée a été collectée sur des filtres Cambridge, qui ont été prétraités avec une solution de dinitrophenylhydrazine (DNPH), suivi d'une chromatographie haute performance en phase liquide (HPLC) des dinitrophénylhydazones dans les composés carbones. Les mégots de cigarettes ont été collectés et analysés pour la nicotine. La teneur en carbonyles dans la fumée inhalée a été calculée en fonction des teneurs en nicotine dans les mégots de cigarettes, basé sur des courbes d'étalonnage. Celles-ci ont été générées séparément en analysant les teneurs en composés carbonyles dans la fumée et la nicotine dans les mégots, obtenues par fumage sur machine selon des conditions normalisées différentes. La comparaison des teneurs en composés carbonyles de la fumée exhalée avec la fumée inhalée montre une rétention importante des carbonyles. La rétention des aldéhydes est supérieure à $95 \%$ pour toutes les cigarettes aux taux différents de goudron. Les cétones sont retenues d'une efficacité légèrement réduite. L'acétone est retenue de $90 \%$ à $95 \%$. La rétention du 2-butanone démontre une plus grande variation par rapport aux autres substances, mais semble être retenue plus faiblement que les aldéhydes, ayant une rétention moyenne autour de $95 \%$. La rétention de l'acétaldéhyde et de l'acétone chez les fumeurs a été rapportée dans la littérature et les données obtenues dans cette étude sont en bon accord avec les résultats rapportés. [Beitr. Tabakforsch. Int. 22 (2007) 346-357]

\section{INTRODUCTION}

The presence of aldehydes and ketones in mainstream cigarette smoke has been reported more than 40 years ago [see e.g. $(1,2)]$. There is interest in the level of carbonyl compounds in cigarette smoke since formaldehyde, acetaldehyde, acrolein, and crotonaldehyde are biologically active agents (3). For this reason, many studies have reported the level of carbonyl compounds in mainstream (4-7) and in sidestream (8) cigarette smoke. Nevertheless, a more accurate and complete evaluation of the effects of cigarette smoke requires, besides the knowledge of the level of specific compounds in smoke, an understanding of the retention of these components by smokers. For nearly 100 years scientists have shown interest in the chemistry and composition of exhaled tobacco smoke (9). However, only three reports published in the literature (10-12) discuss the retention of carbonyl compounds from cigarette smoke. In two of these reports $(10,11)$, acetaldehyde was retained at $99 \%$ (with a variability of $1 \%$ ) and acetone was retained at $86 \%$ (with a variability of $5.5 \%$ ). The studies were preformed on 16 subjects with non-filter cigarettes having $30 \mathrm{mg}$ of total particulate matter (TPM). The third study (12) indicates the global retention of aldehydes and ketones as $99 \%$. The only other information on the retention of carbonyl compounds in smoke comes from an internal British American Tobacco (BAT) report referenced in peer reviewed literature (13), which describes a study done on 4 subjects with 4-6 replicates each, with inhalation and exhalation patterns not controlled. The BAT study reported retention efficiencies for acetaldehyde of $97 \%$ (with a variability of $1.5 \%$ ), $92 \%$ (with a variability of $5.4 \%$ ) for acetone, and $70 \%$ for acrolein (with only one value). Since a very limited number of recent publications describe the retention of carbonyl compounds from cigarette smoke, a more systematic evaluation was considered necessary. The cigarettes selected for the present study were three common commercially available cigarettes of different 'tar' levels, including a $5.0 \mathrm{mg}$ 'tar', a $10.6 \mathrm{mg}$ 'tar', and a $16.2 \mathrm{mg}$ 'tar' products [where 'tar' is defined as the TPM minus the weight of nicotine and water, and the cigarettes are smoked following U.S. Federal Trade Commission (FTC) recommendations (14)]. Given that smoking behavior (i.e. puff volume, puff frequency, puff duration, potential vent-blocking, and other various inhalation behaviors) is known to vary from one subject to 
Table 1. Description of tested cigarettes

\begin{tabular}{lcc|c|}
\hline Descriptor & 16.2 mg 'tar' & 10.6 mg 'tar' & 5.0 mg 'tar' \\
\hline FTC 'tar' (mg/cig) & 16.2 & 10.6 & 5.0 \\
Cigarette length (mm) & 83 & 83 & 83 \\
Filter length (mm) & 21 & 27 & 27 \\
Filter ventilation (\%) & 23 & 32 & 54 \\
Blend type & American & American & American \\
Nicotine (mg/cig) & 1.31 & 0.92 & 0.5 \\
CO (mg/cig) & 13.9 & 10.7 & 7.4 \\
\hline
\end{tabular}

another, and at different times even for the same smoker, this study provides only a limited 'snapshot' on the retention efficiency of carbonyl compounds from mainstream cigarette smoke. Also, a larger variety of cigarette styles, would be desirable for a more in-depth evaluation of the quantitation of carbonyls in exhaled cigarette smoke. In addition to that, in the measurement of the retention efficiency, it is assumed that aldehydes and ketones are not exhaled as different compounds resulting from immediate reactions.

\section{EXPERIMENTAL}

The present study has been performed on three cigarettes with different 'tar' levels (cigarettes being smoked following FTC recommendations (14)]. The description of the cigarettes tested is given in Table 1 . The analysis of carbonyl compounds in the cigarette smoke employed an high performance liquid chromatography (HPLC) procedure using derivatization of the carbonyl compounds with 2,4-dinitrophenylhydrazine (DNPH). This procedure has been commonly practiced for carbonyl compounds analysis and is frequently reported in the literature $(6,8,15-17)$. The experimental procedure of this study consists of several steps. These include: 1) collection of carbonyl compounds from the mainstream cigarette smoke obtained with a smoking machine using a variety of smoking conditions, 2) collection of carbonyl compounds from the exhaled cigarette smoke, 3 ) measurement of collected carbonyl compounds using an HPLC method in the mainstream smoke obtained from the smoking machine, and from the smoke exhaled by the human subjects, 4) analysis of nicotine in the cigarette butts from the smoking machine and from smokers, and 5) calculation of the results. Each of these steps will be discussed in detail in sections that follow.

\section{Collection of samples from smoking machine}

The carbonyl compounds in mainstream cigarette smoke are present in both vapor phase and particulate phase (18). For this reason, the carbonyls from the whole mainstream smoke was collected via a derivatization protocol, which retains both the vapor- and particulate-phase carbonyls on a Cambridge pad. For cigarettes with the TPM level up to about $15 \mathrm{mg} / \mathrm{cig}$, the smoke from five cigarettes was collected on one $92 \mathrm{~mm}$ Cambridge pad pretreated with a DNPH solution in aceto nitrile (DNPH from Aldrich/Sigma, Saint Louis, MO 63178-9916). For cigarettes generat- ing a higher TPM level (e.g., due to more intense smoking conditions), the smoke must be collected on two pads, in order to avoid any breakthrough of the analytes. The pads were prepared by the following procedure: $3 \mathrm{~g}$ of recrystallized DNPH are dissolved in acetonitrile in a $200 \mathrm{~mL}$ volumetric flask, to which $600 \mu \mathrm{L}$ of $70 \%$ perchloric acid is also added. Then, the volumetric flask was brought to $200 \mathrm{~mL}$ with acetonitrile. Twelve $92 \mathrm{~mm}$ Cambridge pads were saturated with this solution by dispensing $100 \mathrm{~mL}$ solution over the pads which were kept in a Petri dish. More or less pads can be prepared as needed, using proportional volumes of solution. The pads, which practically absorb all the solution, are partially dried at room temperature under vacuum, until they reach a weight between 4 and $5 \mathrm{~g}$. A larger weight due to higher acetonitrile content may give problems with solution coming out from the pad during smoking. Pads with less acetonitrile have a reduced reactivity to carbonyl compounds and the recovery of the compounds of interest from smoke may not be complete. After preparation, the pads which were not used immediately were kept in a confined space (such an empty dessicator) saturated with acetonitrile vapors.

Machine smoking has been done in various conditions such as those using the same puff volume and frequency as recommended by the FTC (14), or in specific intensive smoking conditions (19). A Borgwaldt RM 20/CSR smoking machine was used to perform smoking and the sample collection. After smoking, the pads were put in an extraction vial (of about $100 \mathrm{~mL}$ ) and allowed to stand for about 10 min such that any further reaction between DNPH and the carbonyl compounds was completed. During smoke collection, the carbonyl compounds react with the DNPH reagent forming the corresponding substituted hydrazones. Since the reactivity increases for a protonated substituted hydrazine, the addition of a small quantity of perchloric acid was necessary during the pad preparation. Collection efficiency by this procedure was previously verified to be very good (6). However, the presence of a strong acid is undesirable for the chromatographic separation. For this reason, the extraction solution, which consisted of $25 \mathrm{~mL}$ of acetonitrile, contained $2 \%$ pyridine. The same extraction solution also contained $4 \mu \mathrm{g} / \mathrm{mL}$ 1,5-dinitronaphthalene (from Aldrich/Sigma), which was used to verify the stability of the chromatography. The pyridine was added to neutralize the acid and also to stabilize the DNPH derivatives. The pads were extracted on a mechanical shaker for 30 min. A small volume of the extract of each pad were transferred into an HPLC vial and analyzed.

\section{Exhaled smoke collection}

The collection of the exhaled smoke has been done using a simple device schematically shown in Figure 1. The device consisted of a $92 \mathrm{~mm}$ Cambridge holder and a pad pretreated with DNPH having at one opening a replaceable mouth piece, and at the other opening being connected to a diaphragm vacuum pump, which can aspirate $2.2 \mathrm{~m}^{3} / \mathrm{h}$ (Vacuumbrand GMBH, Wertheim, Germany). Through the treated pad and the connecting tubing, the pump achieves about $250 \mathrm{~mL} / \mathrm{sec}$ flow. The tube connecting the pad holder to the pump had two large holes to the exterior, which can be covered with two fingers. When no smoke is exhaled, 


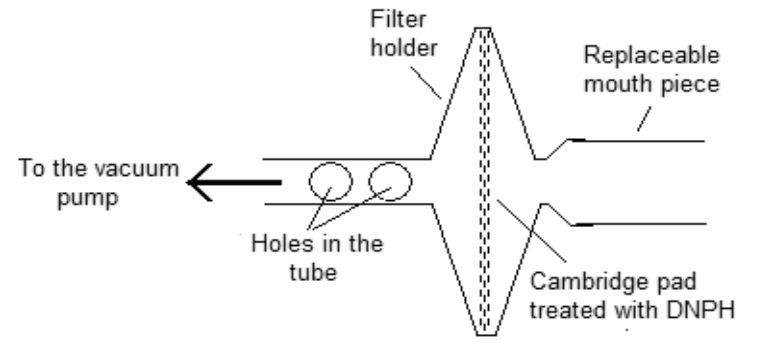

Figure 1. Device for the collection of exhaled cigarette smoke

the holes in the tube to the vacuum pump were kept open such that surrounding air is aspirated by the pump without passing the Cambridge filter. During smoke exhaling, the smoker blows the smoke through the replaceable mouth piece. At the same time the two holes in the tube should be covered with two fingers, such that the exhaled smoke is aspirated through the Cambridge pad pretreated with the DNPH solution in acetonitrile (the pads used for collecting carbonyl compounds from the smokers were prepared identically as those used for the smoking machine). This allows the carbonyl compounds from the exhaled smoke to be collected on the pad, without additional strain on the smoker. Considerable strain would be necessary otherwise to overcome the flow resistance of the Cambridge pad. The device shown in Figure 1 has been used by ten human subjects for testing the $10.6 \mathrm{mg}$ 'tar' cigarette, by five human subjects for the $16.2 \mathrm{mg}$ 'tar' cigarette and other five for the $5.0 \mathrm{mg}$ 'tar' cigarette. Each human subject was a smoker of the particular brand tested. Three cigarettes were smoked for each trial within one hour, and the exhaled smoke was collected on one pad.

One concern regarding the collection of exhaled smoke was the modification of the collection efficiency due to a higher flow rate through the pad compared to that from a smoking machine (with a flow rate between $17.5 \mathrm{~mL} / \mathrm{sec}$ and 30 $\mathrm{mL} / \mathrm{sec}$ through the pad). To prove the efficiency for the retention of carbonyls with the collection device for exhaled smoke, a second filter holder with a Cambridge pad treated with DNPH was connected in series to the vacuum pump. Also a cigarette holder was connected to the mouth piece end of the first filter holder. Using this setup, three $10.6 \mathrm{mg}$ 'tar' cigarettes were smoked each for three intervals of $1 \mathrm{sec}$ with $30 \mathrm{sec}$ smoldering interval. The carbonyls on the two treated Cambridge pads were collected and analyzed separately.

The attention in this study was not focused on the influence of different parameters from the smoking behavior (20) on the retention of carbonyls. The smoking was performed in an environment familiar to the smoker (office) with as little change as possible from typical conditions and with no control on the inhalation or exhalation patterns. The cigarettes were previously conditioned under FTC recommendations. The cigarette butts from the smokers were collected for further nicotine analysis. In addition to exhaled smoke, the breath without smoking was collected from two smokers as a background check. The measurement was done by collecting on a treated Cambridge pad the exhaled air from 24 breaths (mimicking the number of puffs from three cigarettes) after one hour of smoking the last cigarette.
Table 2. HPLC gradient conditions

\begin{tabular}{l|c|c|c}
\hline Time (min) & Solvent A\% & Solvent B\% & Flow mL/min \\
\hline 0.0 & 100 & 0 & 1.5 \\
15.0 & 70 & 30 & 1.5 \\
25 & 43 & 57 & 1.5 \\
30 & 15 & 85 & 1.5 \\
37 & 15 & 85 & 1.5 \\
40 & 100 & 0 & 1.5 \\
43 & 100 & 0 & 1.5 \\
\hline
\end{tabular}

The pads from each source were further extracted with $25 \mathrm{~mL}$ of acetonitrile containing $2 \%$ pyridine and $4 \mu \mathrm{g} / \mathrm{mL}$ 1,5-dinitronaphthalene, in a similar manner to the machine smoked pads. A few milliliter of solution from each pad were transferred into an HPLC vial for analysis.

\section{HPLC analysis}

The analysis of pad extracts was done using an HPLC instrument (Agilent 1050 with a diode array UV detector, Agilent, Wilmington, Delaware 19808). The HPLC instrument was equipped with a Luna C18 column $250 \times 4.6 \mathrm{~mm}$ packed with 5 micron packing material (Phenomenex, Torrance, CA 90501-1430). The injection volume was $5 \mu \mathrm{L}$ for machine smoked pads and a $10 \mu \mathrm{L}$ injection volume was used for the human smoked pads (the chromatographic peak areas were proven proportional to the injection volume). The chromatographic column was maintained at $40{ }^{\circ} \mathrm{C}$. The elution was done using a gradient of two solvents indicated as A and B. Solvent A was prepared from $59 \%$ water, $30 \%$ acetonitrile, $10 \%$ tetrahydrofuran and $1 \%$ isopropanol. Solvent B was prepared from $33 \%$ water, $65 \%$ acetonitrile, $1 \%$ tetrahydrofuran and $1 \%$ isopropanol (5). The parameters for the HPLC gradient (linear) are given in Table 2. Using the conditions from Table 2, and the measurement of UV absorption at $360 \mathrm{~nm}$, the chromatogram generated by the $10.6 \mathrm{mg}$ 'tar' cigarette machinesmoked in FTC type conditions is shown in Figure 2. As seen from Figure 2, acetaldehyde generates two chromatographic peaks, corresponding to the syn and anti forms of the substituted hydrazone. The peak areas from the chromatograms (the sum of the two peaks for acetaldehyde) were used for the quantitation, based on calibration curves for each analyte.

\section{Analysis of nicotine in the cigarette butts}

Based on previously reported results $(21,22)$, the nicotine in the cigarette butt ( $1 \mathrm{~cm}$ from the mouth end) has a linear dependence on the amount of nicotine collected on the Cambridge pad. In this study, correlation curves between the level of carbonyl compounds in smoke and the nicotine level in the cigarette butts were obtained such that the calculation of the level of carbonyls in the smoke delivered to the smoker was possible when the level of nicotine in the cigarette butt was known. For the analysis of nicotine butt, the smoked butts were collected and cut at lengths of $1 \mathrm{~cm}$. The $1 \mathrm{~cm}$ mouth end portions were put together from each smoker, or from the smoking machine, and were extracted 


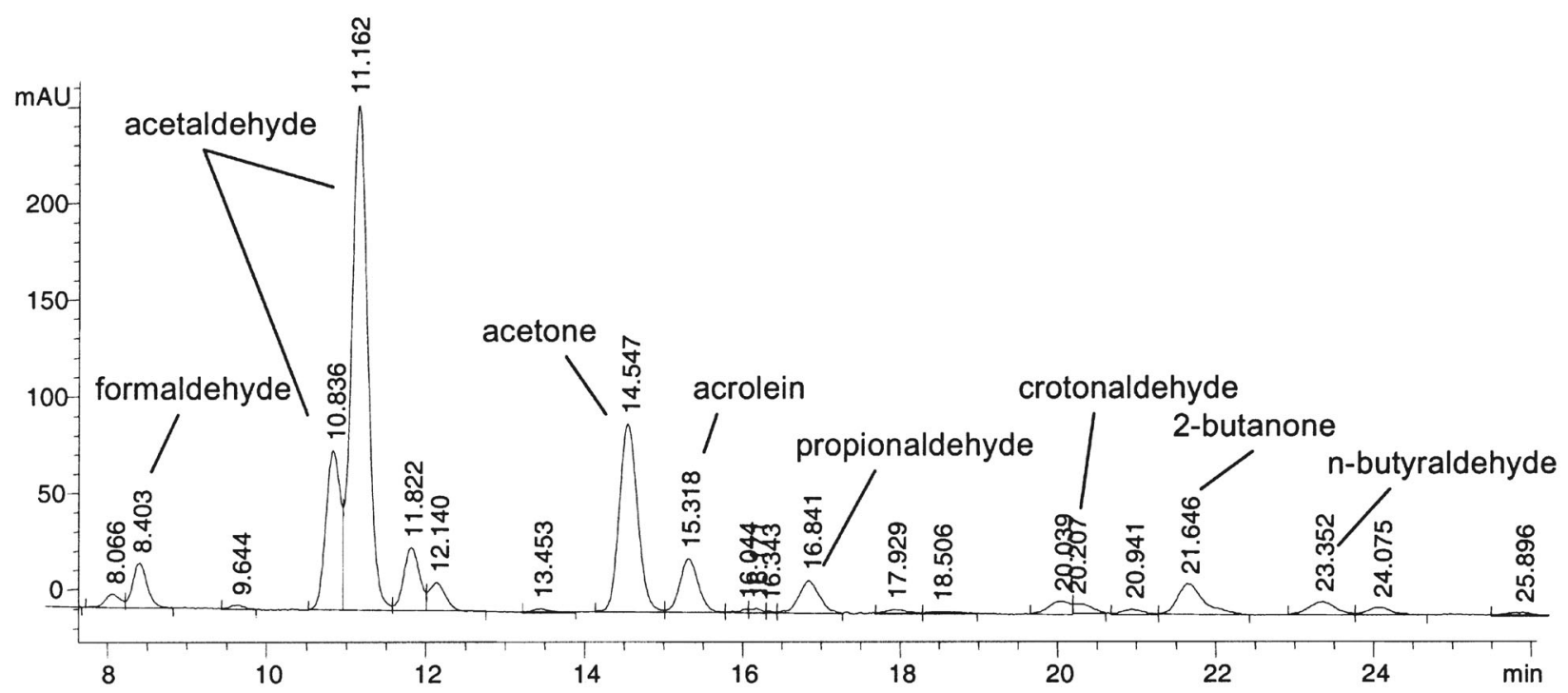

Figure 2. Chromatogram generated from the smoke of a $10.6 \mathrm{mg}$ 'tar' cigarette (5 cigarettes) under FTC smoking conditions

Table 3. Concentrations in $\mu \mathrm{g} / \mathrm{mL}$ of calibration solutions needed to cover the range of concentrations typically found in cigarette smoke and in the exhaled smoke

\begin{tabular}{l|c|c|r|r|r}
\hline Compound & Level 1 & Level 2 & Level 3 & Level 4 & Level 5 \\
\hline Formaldehyde & 0.198 & 0.396 & 1.500 & 3.000 & 6.000 \\
Acetaldehyde & 0.495 & 0.990 & 3.750 & 7.500 & 15.000 \\
Acetone & 0.825 & 1.650 & 6.250 & 12.500 & 3.000 \\
Acrolein & 0.198 & 0.396 & 1.500 & 3.000 & 6.000 \\
Propionaldehyde & 0.198 & 0.396 & 1.500 & 3.000 & 6.000 \\
Crotonaldehyde & 0.198 & 0.396 & 1.500 & 3.000 & 12.000 \\
2-Butanone & 0.198 & 0.396 & 1.500 & 3.000 & 12.000 \\
$n$-Butyraldehyde & 0.132 & 0.264 & 1.000 & 2.000 & 6.000 \\
\hline
\end{tabular}

Table 4. The equations for linear calibration curves for carbonyl quantitations, and the corresponding $R^{2}$ values.

\begin{tabular}{l|c|c}
\hline Compound & \multicolumn{1}{|c}{ Equation } & $R^{2}$ \\
\hline Formaldehyde & $y=0.0034 x+0.0053$ & 0.9993 \\
Acetaldehyde & $y=0.0049 x+0.0655$ & 0.9982 \\
Acetone & $y=0.0061 x+0.1372$ & 0.9981 \\
Acrolein & $y=0.0058 x-0.0456$ & 0.9980 \\
Propionaldehyde & $y=0.0065 x+0.0527$ & 0.9970 \\
Crotonaldehyde & $y=0.0062 x+0.0692$ & 0.9964 \\
2-Butanone & $y=0.0094 x+0.1369$ & 0.9934 \\
$n$-Butyraldehyde & $y=0.0074 x+0.0669$ & 0.9953 \\
\hline
\end{tabular}

with $20 \mathrm{~mL}$ methanol containing an internal standard (dodecanol). The level of nicotine was measured using a standard GC procedure (21).

\section{Calculation of the levels of carbonyl compounds}

For the quantitation of carbonyl compounds in cigarette smoke, calibration curves were generated for all eight carbonyl compounds. Pure DNPH derivatives of the eight carbonyl compounds are commercially available as analytical standard solutions in acetonitrile (Supelco, Bellefonte, PA, 16823). The concentrations in $\mu \mathrm{g} / \mathrm{mL}$ of six standard solutions in acetonitrile were prepared to cover the range of concentrations typically found in cigarette smoke and the low levels found in exhaled smoke are given in Table 3. Using these standard solutions, linear calibration curves were generated for all analytes. The equations for these curves (where $y=$ concentration., $x=$ peak area), as well as the $R^{2}$ values for the trendline are given in Table 4 (using 5 $\mu \mathrm{L}$ injections). Table 4 shows that the $R^{2}$ coefficients for the regression lines are very close to 1 , indicating excellent linearity of the procedure. The change of the injection volume in the HPLC system from $5 \mu \mathrm{L}$ to $10 \mu \mathrm{L}$ and to 20 $\mu \mathrm{L}$ showed perfect linearity for all analytes. For this reason, the samples generated by the smoking machine were analyzed with $5 \mu \mathrm{L}$ injection, while the samples generated by the human subjects were analyzed with $10 \mu \mathrm{L}$ injection. Appropriate volume correction factors were applied in determining the carbonyl levels.

An additional factor that must be considered for the quantitation is that during storage the pads treated with DNPH may collect traces of carbonyl compounds from the environment. Also, the DNPH used to prepare the pads (although recrystallized) may contain trace impurities of analytes. Occasionally, during the analysis of mainstream smoke formaldehyde and acetone, control DNPH-treated pads that were never intentionally exposed to smoke generated sometimes non-zero values for these analyses. It 


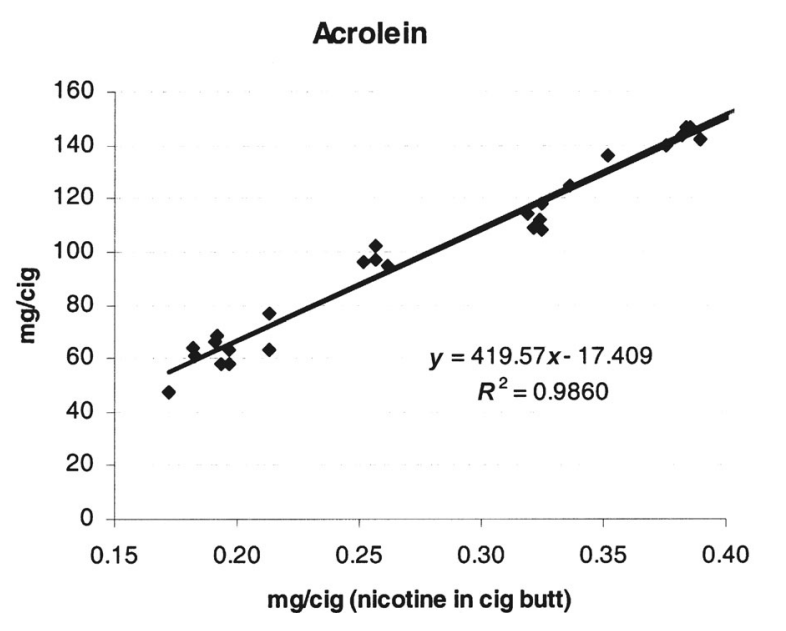

Figure 3. Example of a regression line between the levels of acrolein in the smoke of a $10.6 \mathrm{mg}$ 'tar' cigarette and the level of nicotine in the smoked cigarette butts

is therefore recommended to obtain a baseline value for the carbonyl compounds from one treated pad within a batch, prior to smoking. For this purpose, one treated pad which was not used for smoke collection was extracted and analyzed similar to the pads used for smoke collection. The values obtained for this pad for the carbonyl compounds were subtracted from the values of the samples.

\section{RESULTS AND DISCUSSION}

The analysis of carbonyl compounds was done initially for machine smoked cigarettes using different puffing conditions. At the same time with the analysis of carbonyl compounds from the smoke, nicotine was analyzed in the cigarette butts. Correlation charts between the level of carbonyl compounds in smoke as a function of the nicotine level in the cigarette butts were obtained. Using these charts the calculation of the level of carbonyls in cigarette smoke was possible when the level of nicotine in the cigarette butt was known. After this part of the study had been completed, the exhaled smoke from cigarettes was analyzed for the carbonyl compounds. The level of carbonyls in exhaled smoke was then compared to that in the inhaled smoke and specific carbonyl retention efficiencies were calculated for each smoker.

Generation of the correlation charts between the level of carbonyl compounds for machine smoked cigarettes and cigarette butt nicotine

In order to determine the amount of carbonyl compounds in the inhaled smoke, the regression lines between the level of carbonyl compounds in smoke as a function of the nicotine level in the cigarette butts were generated. The study was initially done for the $10.6 \mathrm{mg}$ 'tar' cigarettes, which were smoked in different puffing conditions. These conditions included FTC type smoking ( $35 \mathrm{~mL}$ puff, $2 \mathrm{sec}$ puff, $60 \mathrm{sec}$ puff interval), 45/60 smoking ( $45 \mathrm{~mL}$ puff, $2 \mathrm{sec}$ puff, $60 \mathrm{sec}$ puff interval), 45/30 smoking (45 mL puff, $2 \mathrm{sec}$ puff, $30 \mathrm{sec}$ puff interval), 60/60 smoking ( $60 \mathrm{~mL}$ puff, $2 \mathrm{sec}$ puff, $60 \mathrm{sec}$ puff interval), and 60/30 smoking (60 mL puff, $2 \mathrm{sec}$ puff, 30
Table 5. The equations of the trendline describing the dependence for the eight carbonyl compounds on the nicotine butt level for the $10.6 \mathrm{mg}$ 'tar' cigarettes, and the corresponding $R^{2}$ values

\begin{tabular}{l|c|c}
\hline Compound & \multicolumn{1}{|c}{ Equation } & $R^{2}$ \\
\hline Formaldehyde & $y=347.32 x-40.463$ & 0.9934 \\
Acetaldehyde & $y=3202.7 x-41.096$ & 0.9786 \\
Acetone & $y=1275.8 x-19.934$ & 0.9884 \\
Acrolein & $y=419.57 x-17.409$ & 0.9860 \\
Propionaldehyde & $y=230.99 x+5.1103$ & 0.9089 \\
Crotonaldehyde & $y=151.56 x-10.01$ & 0.9342 \\
2-Butanone & $y=247.52 x+4.9747$ & 0.9734 \\
$n$-Butyraldehyde & $y=201.9 x-11.476$ & 0.9886 \\
\hline
\end{tabular}

Table 6. The equations of the trendline describing the dependence for the eight carbonyl compounds on the butt nicotine level for the $16.2 \mathrm{mg}$ 'tar' cigarette, and the corresponding $R^{2}$ values

\begin{tabular}{l|c|c}
\hline Compound & Equation & $R^{2}$ \\
\hline Formaldehyde & $y=196.1 x+5.27$ & 0.8610 \\
Acetaldehyde & $y=2918.3 x-84.50$ & 0.9039 \\
Acetone & $y=1280.5 x-24.08$ & 0.9722 \\
Acrolein & $y=366.0 x-8.60$ & 0.9814 \\
Propionaldehyde & $y=279.2 x-15.33$ & 0.9422 \\
Crotonaldehyde & $y=100.2 x-7.32$ & 0.9419 \\
2-Butanone & $y=298.7 x-30.24$ & 0.9437 \\
$n$-Butyraldehyde & $y=166.8 x-6.82$ & 0.9456 \\
\hline
\end{tabular}

sec puff interval). For the $16.2 \mathrm{mg}$ 'tar' and for the $5.0 \mathrm{mg}$ 'tar' cigarettes, only three different smoking conditions were used, these included the FTC type smoking ( $35 \mathrm{~mL}$ puff, 2 sec puff, $60 \mathrm{sec}$ puff interval), 45/30 smoking (45 mL puff, $2 \mathrm{sec}$ puff, $30 \mathrm{sec}$ puff interval), and 60/30 smoking (60 mL puff, $2 \mathrm{sec}$ puff, $30 \mathrm{sec}$ puff interval). No vent blocking was performed on cigarettes. The measurements for the levels of carbonyls were done using the collection and HPLC procedure previously described in the experimental section. At the same time when the carbonyl measurement was performed, the nicotine level in the butts of the machine smoked cigarettes was measured. An example of a regression line obtained in this part of the study for acrolein is given in Figure 3. The equations for the trendline describing the dependence for all eight carbonyl compounds on the nicotine butt level, and the corresponding $R^{2}$ values are given in Table 5 for the $10.6 \mathrm{mg}$ 'tar' product. The linearity between the carbonyl levels and the nicotine butt was verified only for the range $1.7 \mathrm{mg}$ to 4.2 $\mathrm{mg}$ nicotine. This range was later proven to bracket the results for human smoking of that particular cigarette.

Similar dependences were generated for the $16.2 \mathrm{mg}$ 'tar' cigarette (given in Table 6) and for the $5.0 \mathrm{mg}$ 'tar' cigarette (given in Table 7). The linearity between the carbonyl levels and the nicotine butt was verified for the $16.2 \mathrm{mg}$ 'tar' cigarette only for the range $2.3 \mathrm{mg}$ to $4.4 \mathrm{mg}$ nicotine. This range was later proven to bracket the results for human smoking of the $16.2 \mathrm{mg}$ 'tar' cigarette. For the $5.0 \mathrm{mg}$ 'tar' cigarette the linearity between the carbonyl levels and the nicotine butt was verified only for the range $1.5 \mathrm{mg}$ to 3.4 $\mathrm{mg}$ nicotine. This range also was later proven to bracket the results for human smoking of that particular cigarette. 
Table 7. The equations of the trendline describing the dependence for the eight carbonyl compounds on the butt nicotine level for the $5.0 \mathrm{mg}$ 'tar' cigarette, and the corresponding $R^{2}$ values

\begin{tabular}{l|c|c}
\hline Compound & Equation & $R^{2}$ \\
\hline Formaldehyde & $y=167.7 x-15.28$ & 0.9580 \\
Acetaldehyde & $y=3525.9 x-178.67$ & 0.9793 \\
Acetone & $y=1516.2 x-64.58$ & 0.9673 \\
Acrolein & $y=412.4 x-21.69$ & 0.9741 \\
Propionaldehyde & $y=260.3 x+8.90$ & 0.9842 \\
Crotonaldehyde & $y=114.25 x-9.23$ & 0.9158 \\
2-Butanone & $y=338.3 x-18.82$ & 0.9766 \\
$n$-Butyraldehyde & $y=178.8 x-7.56$ & 0.9732 \\
\hline
\end{tabular}

Table 8. Verification of carbonyl retention on a series of two pads using the exhaled smoke collection device when smoking three cigarettes, each for three $1 \mathrm{sec}$ puffing intervals, and $\mathbf{3 0} \mathrm{sec}$ smoldering intervals (average results from duplicate measurements)

\begin{tabular}{l|c|c}
\hline Compound & First pad, $\mu \mathrm{g}$ & Second pad, $\mu \mathrm{g}$ \\
\hline Formaldehyde & 10.50 & 0.50 \\
Acetaldehyde & 412.40 & 4.40 \\
Acetone & 160.71 & 2.72 \\
Acrolein & 42.00 & $\mathrm{ND}^{\mathrm{a}}$ \\
Propionaldehyde & 37.82 & 0.82 \\
Crotonaldehyde & 11.45 & $\mathrm{ND}$ \\
2-Butanone & 30.07 & $\mathrm{ND}$ \\
$n$-Butyraldehyde & 17.11 & $\mathrm{ND}$ \\
\hline
\end{tabular}

${ }^{a} \mathrm{ND}=$ Not detected

In Tables 5 to 7 the $R^{2}$ values for all dependences are high indicating good linearity between the carbonyl level and the nicotine in the cigarette butt. However, the dependence lines do not have a zero intercept (for the best $R^{2}$ values), and are not identical for the three different cigarettes evaluated in this study. This indicated that outside the calibrated range, the dependence between the level of nicotine in the cigarette butt and the individual carbonyl level in smoke is not necessarily linear. The dependence equations should be considered only empirical relations that allow the calculation of the inhaled amount of carbonyl compounds only in the specified range of butt nicotine levels.
Analysis of the carbonyl compounds in exhaled smoke and the calculation of inhaled carbonyl levels

The verification of the efficiency of carbonyl retention using the device for exhaled smoke collection lead to the conclusion that one pad is sufficient for carbonyl collection from the exhaled breath, although the flow through the pad is considerably higher than that for machine smoked cigarettes. The results for the carbonyl levels measured using two pads in series when lit cigarettes were attached to the exhaled smoke collection device, as described in the experimental part, are given in Table 8. Only negligible carbonyl levels were detected on the second treated Cambridge pad.

The next step in the analysis of exhaled smoke evaluation was the measurement of the background level of carbonyl compounds in the breath of two smokers when no cigarette was smoked within one hour. Except for acetone, carbonyl compound levels were below detection limit in the breath (at the sensitivity of the current method). For eight breaths, the acetone level was below $2 \mu \mathrm{g}$, a value accounting for less than $1 \%$ of the acetone level for one cigarette smoked under FTC conditions. For this reason, the background of carbonyl compounds, including acetone, was further neglected in the study. The level of carbonyl compounds in the exhaled smoke was further analyzed for ten smokers of the $10.6 \mathrm{mg}$ 'tar' cigarette and the results are reported in Table 9. The table also indicates the amount of nicotine measured in the collected cigarette butts from each smoker. From the levels of nicotine in the cigarette butt, the calculated inhaled levels of carbonyl compounds are given in Table 10. Using the values from Table 9 and Table 10, a retention efficiency $(\%)$ was calculated for each smoker and for each carbonyl compound, by the following formula:

Retention $(\%)=100-($ Exhaled level $) /($ Inhaled level $) \times 100$

The retention values are plotted in Figure 4, which indicates that the retention of aldehydes from the smoke of the 10.6 mg 'tar' cigarettes approached $100 \%$, while acetone and 2butanone appeared to be slightly less absorbed showing an average retention around $95 \%$. The spread of the results is not very large. Some differences in retention efficiency were noticed from smoker to smoker. For the exhaled smoke some variation may originate in the differences

Table 9. The levels in $\mu \mathrm{g} / \mathrm{cig}$ of carbonyl compounds in the exhaled smoke and the level of nicotine in the cigarette butt in $\mathrm{mg} / \mathrm{cig}$ for each of the human subjects that smoked a $10.6 \mathrm{mg}$ 'tar' cigarette ${ }^{\mathrm{a}}$

\begin{tabular}{l|c|c|c|c|c|c|c|c|c|c}
\hline Compound & Exhaled 1 & Exhaled 2 & Exhaled 3 & Exhaled 4 & Exhaled 5 & Exhaled 6 & Exhaled 7 & Exhaled 8 & Exhaled 9 & Exhaled \\
\hline Formaldehyde & $\mathrm{ND}^{\mathrm{b}}$ & 1.26 & 0.51 & 0.48 & 0.47 & 0.51 & 0.53 & $\mathrm{ND}$ & 0.80 & 1.21 \\
Acetaldehyde & 36.52 & 33.22 & 30.32 & 23.92 & 36.91 & 26.24 & 58.43 & 15.85 & 35.99 & 30.28 \\
Acetone & 24.68 & 20.94 & 18.53 & 12.84 & 25.96 & 13.27 & 33.19 & 22.34 & 24.40 & 18.50 \\
Acrolein & 0.71 & $\mathrm{ND}$ & $\mathrm{ND}$ & $\mathrm{ND}$ & $\mathrm{ND}$ & 0.35 & $\mathrm{ND}$ & 0.72 & ND & 0.05 \\
Propionaldehyde & 3.94 & 0.01 & 0.94 & 0.75 & 1.86 & 1.59 & 2.74 & 0.97 & 2.46 & 1.13 \\
Crotonaldehyde & 1.25 & 0.12 & 0.12 & 0.12 & 1.03 & 0.06 & 0.86 & 0.59 & 1.23 & 0.15 \\
2-Butanone & 5.67 & $\mathrm{ND}$ & 1.64 & 2.63 & 4.74 & 3.08 & 6.66 & 2.05 & 4.34 & 1.48 \\
n-Butyraldehyde & 2.46 & $\mathrm{ND}$ & $\mathrm{ND}$ & $\mathrm{ND}$ & $\mathrm{ND}$ & 0.32 & 0.42 & 0.56 & 1.21 & ND \\
Nicotine in cig butt & 0.241 & 0.241 & 0.290 & 0.207 & 0.383 & 0.180 & 0.318 & 0.373 & 0.228 & 0.277 \\
\hline
\end{tabular}

${ }^{a}$ Human subjects 6 and 7 were the same as 4 and 5 , respectively, smoking in a different day.

${ }^{b} \mathrm{ND}=$ not detected 
Table 10. Calculated levels in $\mu \mathrm{g} / \mathrm{cig}$ of carbonyl compounds in the inhaled smoke for ten human subjects that smoked a $10.6 \mathrm{mg}$ 'tar' cigarette

\begin{tabular}{l|r|r|r|r|r|r|r|r|r|r}
\hline Compound & Inhaled 1 & Inhaled 2 & Inhaled 3 & Inhaled 4 & Inhaled 5 & Inhaled 6 & Inhaled 7 & Inhaled 8 & Inhaled 9 & Inhaled 10 \\
\hline Formaldehyde & 34.02 & 34.02 & 51.04 & 22.21 & 83.34 & 12.83 & 60.76 & 79.73 & 29.78 & 46.52 \\
Acetaldehyde & 730.75 & 730.75 & 887.69 & 621.86 & 1185.54 & 535.39 & 977.36 & 1152.25 & 691.64 & 846.01 \\
Acetone & 287.53 & 287.53 & 350.05 & 244.16 & 468.70 & 209.71 & 385.77 & 455.44 & 271.95 & 333.45 \\
Acrolein & 84.49 & 84.49 & 105.16 & 70.15 & 144.40 & 58.76 & 116.98 & 138.93 & 78.58 & 98.81 \\
Propionaldehyde & 60.78 & 60.78 & 72.10 & 52.93 & 93.58 & 46.69 & 78.57 & 91.18 & 57.96 & 69.09 \\
Crotonaldehyde & 26.52 & 26.52 & 33.94 & 21.36 & 48.04 & 17.27 & 38.19 & 46.46 & 24.66 & 31.97 \\
2-Butanone & 54.68 & 54.68 & 66.81 & 46.26 & 89.83 & 39.58 & 73.74 & 87.25 & 51.65 & 63.59 \\
$n$-Butyraldehyde & 37.18 & 37.18 & 47.08 & 30.32 & 65.85 & 24.87 & 52.73 & 63.75 & 34.72 & 44.45 \\
\hline
\end{tabular}

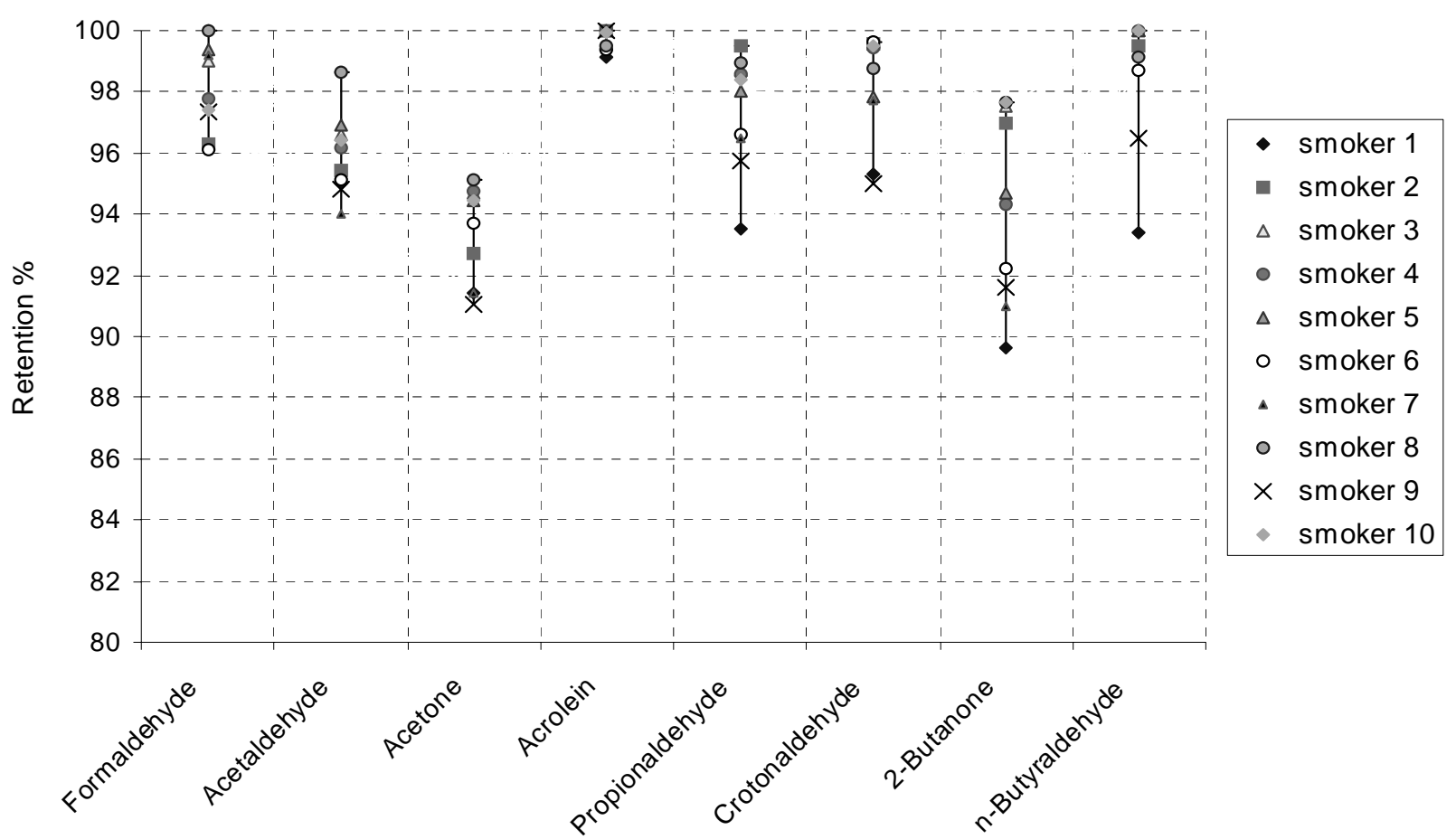

Figure 4. Results regarding the retention \% for eight carbonyl compounds obtained for ten human subjects smoking a 10.6 mg 'tar' cigarette

between the smoking characteristics of each individual, but also may be due to variability in cigarettes, the smoke collection procedure, as well as in the analytical measurements. However, the levels of all carbonyl compounds are very low in the exhaled smoke compared to the levels from the mainstream smoke of the cigarette. Therefore these variations have a small impact on the final retention (\%) values. For the exhaled smoke, the values were calculated based on the nicotine levels in the cigarette butts, and the errors in this measurement were propagated to the carbonyl levels of the inhaled smoke. These measurements are, however, affected only by the error of the analytical methods, and therefore expected to be much lower than those generated in the measurements on the human subjects.

The study was further continued for the $16.2 \mathrm{mg}$ 'tar' and for the $5.0 \mathrm{mg}$ 'tar' cigarettes. The procedure for collecting the smoke, analyzing it and performing the calculations were the same as for the $10.6 \mathrm{mg}$ 'tar' cigarette. The only difference was the number of smokers which was only five for each of the two cigarette styles. The results for the level of carbonyl compounds in the exhaled smoke for the 16.2 mg 'tar' product in $\mu \mathrm{g} / \mathrm{cig}$ as well as the amount of nicotine in $\mathrm{mg} / \mathrm{cig}$ measured in the collected cigarette butts from each smoker are shown in Table 11. From the levels of nicotine in the cigarette butt, the calculated inhaled levels of carbonyl compounds for the $16.2 \mathrm{mg}$ 'tar' cigarette are given in Table 12. Using the values from Table 11 and Table 12, the retention (\%) was calculated for each smoker, the results being plotted in Figure 5 .

The results for the level of carbonyl compounds in $\mu \mathrm{g} / \mathrm{cig}$ in the exhaled smoke for the $5.0 \mathrm{mg}$ 'tar' product as well as the amount of nicotine in $\mathrm{mg} / \mathrm{cig}$ measured in the collected cigarette butts from each smoker are shown in Table 13. From the levels of nicotine in the cigarette butt, the calculated inhaled levels of carbonyl compounds for the $5.0 \mathrm{mg}$ 'tar' cigarette are given in Table 14. Using the values from Table 13 and Table 14, the retention (\%) was calculated for each smoker, the results being plotted in Figure 6. 
Table 11. The levels in $\mu \mathrm{g} / \mathrm{cig}$ of carbonyl compounds in the exhaled smoke and the level of nicotine in the cigarette butt (mg/cig) for each of the five human subjects smoking a $16.2 \mathrm{mg}$ 'tar' cigarette

\begin{tabular}{l|c|c|c|c|c}
\hline Compound & Exhaled 1 & Exhaled 2 & Exhaled 3 & Exhaled 4 & Exhaled 5 \\
\hline Formaldehyde & 2.53 & 2.50 & 1.41 & 0.79 & 0.91 \\
Acetaldehyde & 26.77 & 31.93 & 37.95 & 12.14 & 38.93 \\
Acetone & 61.38 & 74.10 & 58.22 & 56.65 & 43.41 \\
Acrolein & 0.76 & $\mathrm{ND}^{\mathrm{a}}$ & 0.89 & 1.92 & 2.46 \\
Propionaldehyde & 1.68 & $\mathrm{ND}$ & 4.58 & 2.95 & 3.21 \\
Crotonaldehyde & 0.12 & 0.23 & $\mathrm{ND}$ & 0.66 & 0.87 \\
2-Butanone & 1.83 & 1.09 & 6.42 & 5.20 & 3.31 \\
$n$-Butyraldehyde & 2.47 & $\mathrm{ND}$ & 2.47 & 2.50 & 1.12 \\
Nicotine in cig butt & 0.260 & 0.311 & 0.273 & 0.286 & 0.280 \\
\hline
\end{tabular}

${ }^{a} \mathrm{ND}=$ not detected

Table 12. Calculated levels in $\mu \mathrm{g} / \mathrm{cig}$ of carbonyl compounds in the inhaled smoke for each of the five human subjects smoking a $16.2 \mathrm{mg}$ 'tar' cigarette

\begin{tabular}{|c|c|c|c|c|c|}
\hline Compound & Inhaled 1 & Inhaled 2 & Inhaled 3 & Inhaled 4 & Inhaled 5 \\
\hline Formaldehyde & 56.26 & 66.26 & 58.81 & 61.35 & 60.18 \\
\hline Acetaldehyde & 674.26 & 823.09 & 712.20 & 750.13 & 732.63 \\
\hline Acetone & 308.85 & 374.16 & 325.50 & 342.14 & 334.46 \\
\hline Acrolein & 86.54 & 105.20 & 91.30 & 96.05 & 93.86 \\
\hline Propionaldehyde & 57.26 & 71.50 & 60.89 & 64.52 & 62.84 \\
\hline Crotonaldehyde & 18.73 & 23.84 & 20.03 & 21.34 & 20.74 \\
\hline 2-Butanone & 47.43 & 62.66 & 51.31 & 55.19 & 53.40 \\
\hline$n$-Butyraldehyde & 36.55 & 45.05 & 38.71 & 40.88 & 39.88 \\
\hline
\end{tabular}

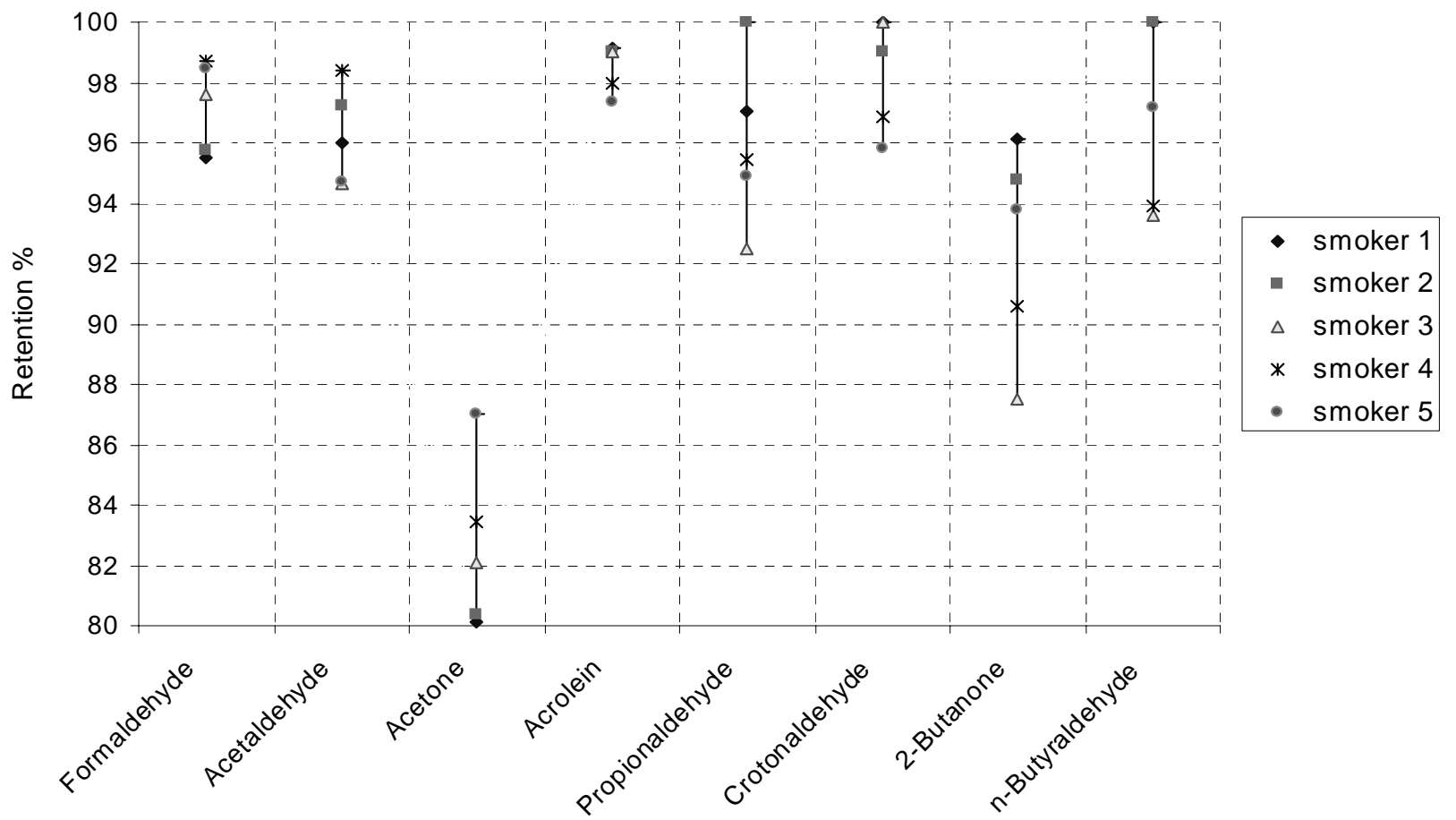

Figure 5. Results regarding the retention \% for eight carbonyl compounds obtained for five human subjects smoking a $16.2 \mathrm{mg}$ 'tar' cigarette

The pattern for the retention of carbonyl compounds for the $16.2 \mathrm{mg}$ 'tar' and for the $5.0 \mathrm{mg}$ 'tar' cigarette is basically the same as the one observed for the $10.6 \mathrm{mg}$ 'tar' cigarette. Some differences were noticed for the 16.2 mg 'tar' product for which the retentions seem to be slightly lower. The retention for aldehydes is high in all cases, while the ketones seem to be retained slightly less than the aldehydes. 
Table 13. The levels in $\mu \mathrm{g} / \mathrm{cig}$ of carbonyl compounds in the exhaled smoke for each of the five human subjects smoking a $5.0 \mathrm{mg}$ 'tar' cigarette

\begin{tabular}{l|c|c|c|c|c}
\hline Compound & Exhaled 1 & Exhaled 2 & Exhaled 3 & Exhaled 4 & Exhaled 5 \\
\hline Formaldehyde & 0.69 & 0.47 & 1.46 & 0.58 & 0.54 \\
Acetaldehyde & 19.10 & 13.07 & 15.20 & 17.78 & 17.54 \\
Acetone & 27.18 & 20.15 & 23.50 & 29.04 & 15.97 \\
Acrolein & $\mathrm{ND}$ & $\mathrm{ND}$ & $\mathrm{ND}$ & 1.11 & 0.55 \\
Propionaldehyde & 0.09 & 0.27 & 0.35 & 0.65 & 0.83 \\
Crotonaldehyde & $\mathrm{ND}$ & $\mathrm{ND}$ & $\mathrm{ND}$ & 0.98 & 0.19 \\
2-Butanone & 2.89 & 4.05 & 1.79 & 1.52 & $\mathrm{ND}$ \\
$n$-Butyraldehyde & 1.87 & $\mathrm{ND}$ & $\mathrm{ND}$ & 0.159 & $\mathrm{ND}$ \\
Nicotine in cig butt & 0.216 & 0.245 & 0.300 & & 0.22 \\
\hline
\end{tabular}

${ }^{a} \mathrm{ND}=$ not detected

Table 14. Calculated levels in $\mu \mathrm{g} / \mathrm{cig}$ of carbonyl compounds in the inhaled smoke for each of the five human subjects smoking a $5.0 \mathrm{mg}$ 'tar' cigarette

\begin{tabular}{lcc|c|c|c}
\hline Compound & Inhaled 1 & Inhaled 2 & Inhaled 3 & Inhaled 4 & Inhaled 5 \\
\hline Formaldehyde & 20.95 & 25.82 & 35.05 & 11.39 & 21.63 \\
Acetaldehyde & 582.92 & 685.18 & 879.10 & 381.95 & 597.03 \\
Acetone & 262.92 & 306.89 & 390.28 & 176.50 & 268.98 \\
Acrolein & 69.33 & 81.55 & 104.72 & 45.31 & 71.01 \\
Propionaldehyde & 47.42 & 54.96 & 69.28 & 32.58 & 48.46 \\
Crotonaldehyde & 15.45 & 18.76 & 25.04 & 8.93 & 15.90 \\
2-Butanone & 54.24 & 64.05 & 82.66 & 34.96 & 55.60 \\
n-Butyraldehyde & 31.07 & 36.26 & 46.09 & 20.88 & 31.79 \\
\hline
\end{tabular}

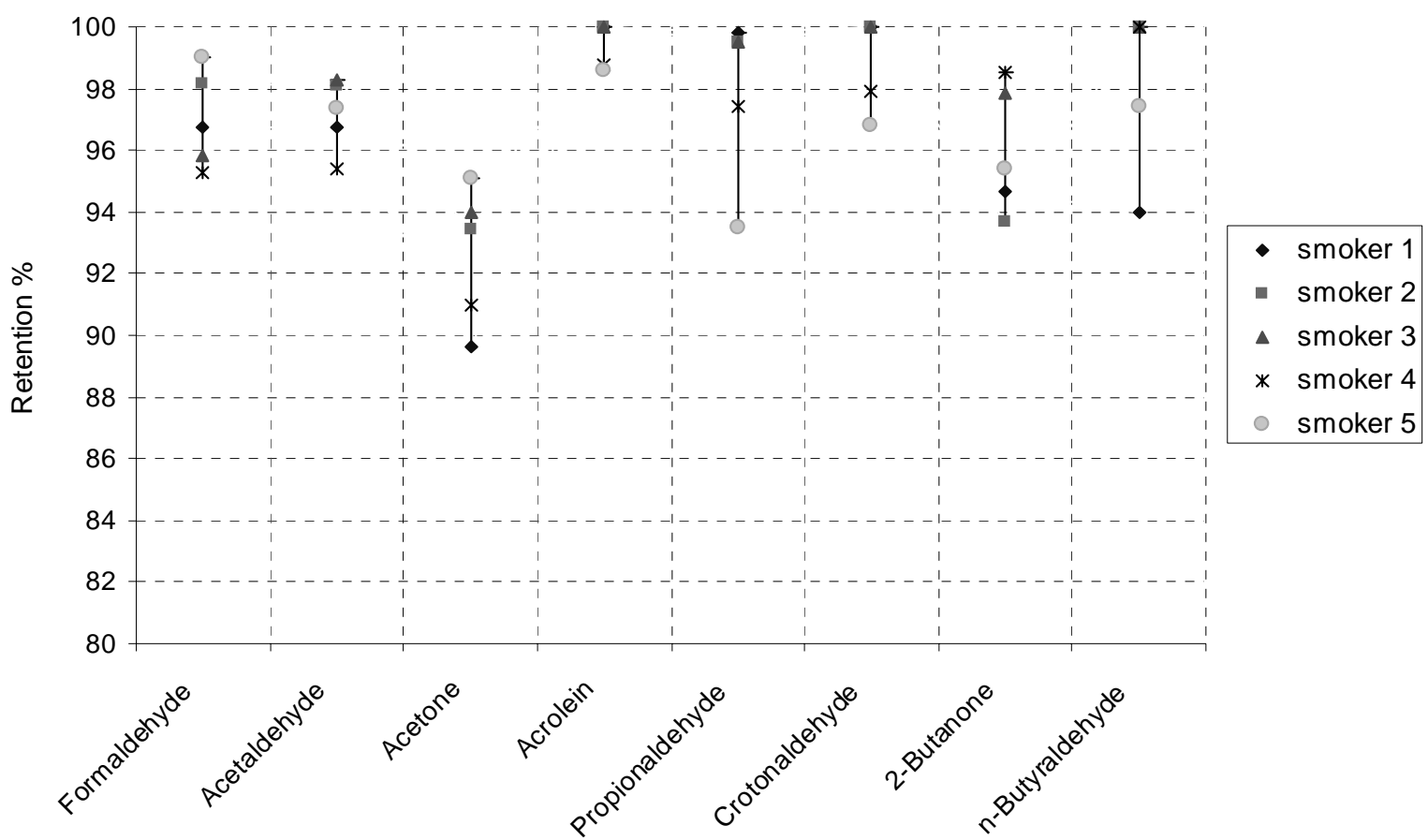

Figure 6. Results regarding the retention \% for eight carbonyl compounds obtained for five human subjects smoking a $5.0 \mathrm{mg}$ 'tar' cigarette

The findings from this study are in very good agreement with the result reported in literature for acetaldehyde and acetone (10-12). Some disagreement exists regarding acrolein, which was found in the present study to be retained more than $96 \%$ for all tested cigarettes. This value is higher than the one value (of 70\%) given in a BAT report (13). Acrolein can be expected to be highly retained since other small aldehydes also are highly retained. Based on 
the results from an overall study on the chemical composition of exhaled cigarette smoke (23), as well as from the properties of acrolein [ $n$-octanol-water partition coefficient $\log P=0.9$ (24)] the expected retention is again high. For these reasons, the $70 \%$ retention can be seen as an underestimation of acrolein retention.

Information on acrolein metabolism and level of urinary biomarkers for this compound is available in literature (25, 26). The main known metabolite of acrolein in urine is 3hydroxypropyl mercapturic acid, which accounts for $23 \%$ (17\% to $29 \%$ ) of the retained compound (25). This result indicates that acrolein from cigarette smoke is only partially excreted in urine as 3-hydroxypropyl mercapturic acid. Other paths, such as bile excretion, smoker breath, etc. may contribute to the excretion of the acrolein retained from smoke.

\section{CONCLUSIONS}

This study reports for the first time the level of eight carbonyl compounds in exhaled cigarette smoke. The cigarettes considered in the study were three cigarettes of different (FTC) 'tar' levels including a $5.0 \mathrm{mg}$ 'tar', a 10.6 $\mathrm{mg}$ 'tar' and a $16.2 \mathrm{mg}$ 'tar' cigarette. The results are reported for formaldehyde, acetaldehyde, acetone, acrolein, propionaldehyde, crotonaldehyde, 2-butanone, and $n$ butyraldehyde. The study was done on ten human subjects for the $10.6 \mathrm{mg}$ 'tar' product, five for the $16.2 \mathrm{mg}$ 'tar', and five for the $5.0 \mathrm{mg}$ 'tar' product. The human subjects were smokers of the respective brand and style. The results showed that the aldehydes were retained above $95 \%$ for all three styles. The ketones were retained with a slightly lower efficiency. Acetone was retained in the range of $90 \%$ to $95 \%$. The retention for 2-butanone showed a larger scatter compared to other results but it also appeared to be slightly less absorbed than the aldehydes, with an average retention around $95 \%$. The retention of acetaldehyde and acetone by human smokers was previously reported in literature and the findings from this study are in very good agreement with these result.

\section{REFERENCES}

1. Grob, K.: Zur Gaschromatographie des Cigarettenrauches: 1. Teil: Eine Methode zur Routine-Analyse der Gas-Dampf-Phase [Gas chromatography in tobacco smoke of cigarettes. Part 1. A method for routine analysis of gas phase]; Beitr. Tabakforsch. 1 (1962) 285-290.

2. Grob, K.: Zur Gaschromatographie des Cigarettenrauches: 2. Teil: Verfeinerte Trennung mit Hilfe von Kapillarkolonnen [Gas chromatography in tobacco smoke of cigarettes. Part 2. Refined resolution by use of Golay column]; Beitr. Tabakforsch. 1 (1962) 315-323.

3. Hoffmann, D. and I. Hoffmann: Tobacco smoke components; Beitr. Tabakforsch. Int. 18 (1998) 49-52.

4. Manning, D.L., M.P. Maskarinec, R.A. Jenkins, and A.H. Marshall: High performance liquid chromatographic determination of selected gas phase carbonyls in tobacco smoke; J. Assoc. Off. Anal. Chem. 66 (1983) 8-12.

5. Arista Laboratories, Standard Operating Procedure T005: The Determination of carbonyls and aldehydes in mainstream and sidestream smoke. Version 1; July 20, 2001.

6. Dong, J.-Z. and S.C. Moldoveanu: Gas chromatography-mass spectrometry of carbonyl compounds in cigarette mainstream smoke after derivatization with 2,4-dinitrophenylhydrazine; J. Chromatogr. A 1027 (2004) 25-33.

7. Chen, P.X. and S.C. Moldoveanu: Mainstream smoke chemical analyses for 2R4F Kentucky reference cigarette; Beitr. Tabakforsch. Int. 20 (2003) 448-458.

8. Risner, C.H. and P. Martin: Quantitation of formaldehyde, acetaldehyde, and acetone in sidestream cigarette smoke by high-performance liquid chromatography; J. Chromatogr. Sci. 32 (1994) 76-82.

9. Lehmann, K.B.: Untersuchungen im Rauche des Tabaks [Investigation of the smoke from tobacco]; Münchener med. Wochenschrift LV (1908) 723-725.

10. Dalhamn, T., M.-L. Edfors, and R. Rylander: Mouth absorption of various compounds in cigarette smoke; Arch. Environ. Health 16 (1968) 831-835.

11. Dalhamn, T., M.-L. Edfors, and R. Rylander: Retention of cigarette smoke components in human lungs; Arch. Environ. Health 17 (1968) 746-748.

12. Laskowski, K.: Components of tobacco smoke and their absorption in the respiratory system of the smoker; Rocz. Państw. Zak. Hig. [Ann. Natl. Inst. Hyg.] 2 (1951) 139-160.

13. Baker, R.R. and M. Dixon: The retention of tobacco smoke constituents in the human respiratory tract; Inhalat. Toxicol. 18 (2006) 255-294.

14. Pillsbury, H.C., C.C. Bright, K.J. O'Connor, and F.H. Irish: 'Tar' and nicotine in cigarette smoke; J. Assoc. Off. Anal. Chem. 52, (1969) 458-462.

15. Lunn, G. and L.C. Hellwig: Handbook of derivatization reactions for HPLC, Wiley, New York, 1998, pp. 211-223, and pp. 1230-1238.

16. Moldoveanu, S.C. and V. David, Sample preparation in chromatography, Elsevier, Amsterdam, 2002, pp. 724-739.

17. Wang, T,L., H.W. Tong, X.Y. Yan, L.Q. Sheng, J. Yang, and S.M. Liu: Determination of volatile carbonyl compounds in cigarette smoke by LC-DAD; Chromatographia 62 (2005) 631-636.

18. Baker, R.R.: Smoke chemistry, in Tobacco production, chemistry and technology, edited by Davis, D.L. and M.T. Nielsen, Blackwell Science, Oxford, Chap. 12, 1999, pp 398-439.

19. Connoly, G.N. and H. Saxner: Memorandum; The Commonwealth of Massachusetts, Exec. Office of Health and Human Services, 19 August 1997.

20. Armitage, A.K., M. Dixon, B.E. Frost, D.C. Mariner, and N.M. Sinclair: The effect of inhalation volume and breath-hold duration on the retention of nicotine and solanesol in the human respiratory tract and on subsequent plasma nicotine concentrations during cigarette smoking; Beitr. Tabakforsch. Int. 21 (2004) 240-249.

21. St.Charles, F.K.: A robust method for determining 
consumer smoked cigarette yields from filter analytical data; $55^{\text {th }}$ Tobacco Science Research Conference, Program Booklet and Abstracts, Vol. 55, Paper No. 92, 2001, pp. 73-74.

22. Bodnar, J.A., T.J. Collins, S.M. DeBusk, and M.F. Borgerding: Estimation of 'tar' and nicotine yields from individual cigarettes based on filter analysis after smoking; 58 ${ }^{\text {th }}$ Tobacco Science Research Conference, Program Booklet and Abstracts, Vol.58, Paper No. 8, 2004, p 25.

23. Moldoveanu, S.C. and K.F. St.Charles: Differences in the chemical composition of particulate phase of inhaled and exhaled cigarette smoke; Beitr. Tabakforsch. Int. 22 (2007) 290-302.

24. Veith, G.D.,K. J. Macek, S. R., Petrocelli, S.R., and J. Carrol: An evaluation of using partition coefficients and water solubility to estimate bioconcentration factors for organic chemicals in fish. Aquat. Toxicol. (1980) 116-129.
25. Mariner D., M. McEwan, K. St.Charles, G. Krautter, and S. Appleton: Dose response relationship for urinary biomarkers of selected tobacco smoke constituents, $58^{\text {th }}$ Tobacco Science Research Conference, Program Booklet and Abstracts, Vol.58, Paper 56, 2004, p. 55.

26. International Program on Chemical Safety, INCHEM, http://www.inchem.org.

Serban Moldoveanu

R.J. Reynolds Tobacco Co.

950 Reynolds Boulevard

Winston-Salem, NC 27105

USA

E-mail:moldovs@rjrt.com 